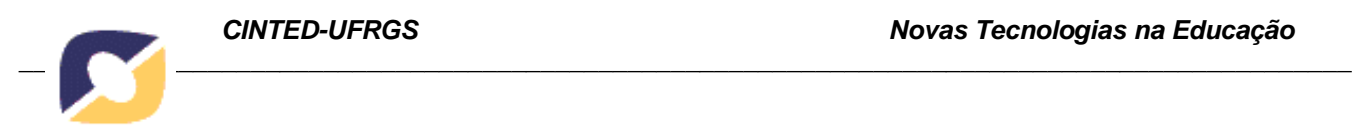

\title{
A interação em ambientes virtuais de aprendizagem: motivações e interesses dos alunos.
}

Ana Luisa Mülbert - Universidade do Sul de Santa Catarina - amulbert@gmail.com

Ariane Girondi - Universidade Federal de Santa Catarina - agirondi@ gmail.com

Alice T. Cybis Pereira - Universidade Federal de Santa Catarina - acybis@ gmail.com

Marina K. Nakayama - Universidade Federal de Santa Catarina - marina@egc.ufsc.br

\section{Resumo}

A interação em ambientes virtuais de aprendizagem (AVAs) é fenômeno de substancial importância para o sucesso de programas de ensino a distância. Neste artigo, discutimos sobre as motivações de alunos para interagir por meio de AVAs. A partir dos diálogos desenvolvidos pelos alunos, foram categorizados os seguintes motivos e interesses: (a) dúvidas operacionais, de conteúdo e de avaliação, (b) iniciativas para a colaboração, (c) desejo de afiliação ao grupo, (d) manifestações de afetividade, (e) negociação e conflitos e (f) desejo de privacidade e não supervisão. Os dados coletados correspondem aos diálogos desenvolvidos entre alunos e professores, em um curso superior a distância, submetidos à análise de seu conteúdo em uma abordagem interpretativista.

Palavras-chave: ambiente virtual de aprendizagem; educação a distância; aprendizagem, motivação.

\section{The interaction in learning management systems: motivations and interests of students.}

\begin{abstract}
The interaction through learning management systems (LMS) is a phenomenon of substantial importance to distance education programs success. In this article we discussed the motivations of students to interact through LMS. From the dialogues developed by the students were ranked the following reasons and concerns: (a) operational questions, content and assessment, (b) initiatives for collaboration, (c) desire for group affiliation, (d) expressions of affection (e) negotiation and conflict and (f) desire for privacy and no supervision. The collected data correspond to the dialogues developed between teachers and students of higher distance courses, subjected to content analysis in an interpretativist approach.
\end{abstract}

Keywords: learning management systems, distance education, learning, motivation.

\section{Introdução}

O rápido crescimento da demanda por conhecimento e atualização, assim como o amadurecimento de tecnologias da informação e da comunicação, têm oportunizado o crescimento significativo da modalidade de educação a distância, frequentemente mediada por Ambientes Virtuais de Aprendizagem (AVAs). Nesta linha, desenvolvemse novos modelos pedagógicos que possibilitam que a educação aconteça muito além dos limites de uma sala de aula convencional, que demandam por novas habilidades na interação e no diálogo entre professor e aluno. 


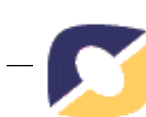

Para compreender melhor o fenômeno da interação que se dá na aprendizagem a distância, este trabalho busca investigar as motivações e interesses de alunos para interagir por meio de AVAs. Esta investigação se dá pela análise dos diálogos iniciados pelos alunos, em um curso superior a distância mediado por AVA, de modo a buscar a compreensão dos motivos e interesses que levam o aluno a interagir. Parte-se do pressuposto de que a iniciativa para estabelecer diálogos por parte do aluno pode revelar seus interesses na interação.

\section{A interatividade em educação a distância}

A educação a distância (EAD) é o processo de ensino-aprendizagem, mediado por tecnologias, no qual professores e alunos estão separados espacial e/ou temporalmente. Segundo Oblinger (2006) os recursos tecnológicos contribuem para redefinir os espaços de aprendizagem. Na EAD os espaços físicos são substituídos por espaços virtuais apresentados na forma de ambientes virtuais de aprendizagem, que fornecem ferramentas para mediar o processo educacional. A interatividade no desenvolvimento das atividades é um fenômeno importante, que precisa ser bem compreendido para que se possa propor práticas pedagógicas adequadas.

A interação que ocorre na EAD deve ser vista como um fenômeno pedagógico e não simplesmente como uma mera questão de distância geográfica. A distância física conduz a um hiato na comunicação, um espaço psicológico de concepções errôneas potenciais entre instrutores e alunos, que precisa ser suplantado por técnicas especiais de ensino. A superação da distância se dá por meio de procedimentos diferenciadores na elaboração da instrução e na facilitação da interação (Moore, 2007).

A distância física entre professor e aluno é tão significativa que chega ao ponto de afetar seus comportamentos e interferir em seus diálogos. Os diálogos escritos tendem a ser mais formais e estruturados do que os diálogos baseados na oralidade. Quando o diálogo se dá por meio de ferramentas on line tende a ser, também, muito mais frequente e rápido se comparado com outros meios também utilizados em EAD como a correspondência, o áudio e as videoconferências (frequentemente unilaterais) (Moore, 2007).

A interação entre aluno-professor e aluno-aluno é um processo complexo que interfere significativamente no processo de aprendizagem, sobretudo, quando se espera que esta interação se dê de modo colaborativo e fortemente centrada no aluno. Esta interação é, portanto, um fenômeno que precisa ser bem compreendido. Por isso, neste artigo, investigamos os motivos e interesses que levam o aluno a interagir de modo a contribuir para o entendimento mais aprofundado desse processo.

\section{Contexto da pesquisa}

O objeto de pesquisa deste estudo são as interações realizadas pelos alunos em um curso de graduação brasileiro, que se dá no contexto do Campus Virtual da Universidade do Sul de Santa Catarina - UNISUL. A instituição desenvolve sua própria metodologia e demais recursos para implementar programas de ensino a distância. As ações pedagógicas desenvolvidas se baseiam em recursos didáticos, sistema tutorial, suporte tecnológico e avaliação da aprendizagem. Estes recursos e métodos, combinados entre si, apóiam uma metodologia de estudos a distância na qual o aluno interage com os recursos didáticos, com o professor e com os colegas em atividades 


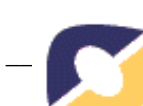

individuais e colaborativas por meio de um AVA. Além da disponibilidade de recursos síncronos (chats e videoconferências), a maior ênfase das comunicações se dá por ferramentas de comunicação assíncrona como fóruns, tira-dúvidas, murais, exposições, etc. O sistema tutorial corresponde à sistemática de atendimento e mediação pedagógica, no qual se destacam a atuação do professor, dos monitores e do coordenador do curso.

Para o desenvolvimento desta pesquisa, coletamos dados em duas ferramentas do AVA: as ferramentas Professor e Turma. A ferramenta Professor é um recurso assíncrono que o aluno utiliza para interagir diretamente com o professor por livre iniciativa, para registrar comentários, dúvidas ou qualquer outro apontamento que julgue pertinente.

Nela o professor responde as dúvidas ou complementa os comentários dos alunos. Esse diálogo é visível para toda a turma e pode ser livremente acessado por qualquer participante. A ferramenta Turma possibilita ao aluno comunicar-se com seus colegas por correio eletrônico e o AVA armazena cópia de todas as comunicações nele iniciadas. Essas duas ferramentas estão disponíveis em todas as disciplinas cursadas pelo aluno e se constituem no principal canal de comunicação pelo qual o aluno pode iniciar algum diálogo. Outras ferramentas, como Exposição e Fórum, são freqüentemente utilizadas para o cumprimento de atividades formais de avaliação propostas pelo professor. Por este motivo não foram utilizadas para diagnosticar iniciativas espontâneas dos alunos.

Quanto ao perfil dos alunos do curso em análise, no primeiro semestre de 2010, o curso acolheu $86 \%$ de participantes do sexo masculino, com $65 \%$ dos alunos concentrados na faixa etária de 25 a 39 anos e $75 \%$ já atuando profissionalmente na área de conhecimento do curso. Esses dados revelam um público maduro e com uma carreira profissional já em andamento.

\section{Procedimentos metodológicos}

Nesta pesquisa, analisamos os diálogos desenvolvidos no AVA pela perspectiva interpretativista de modo a compreender em profundidade o significado das interações.

Os diálogos entre alunos e professor foram extraídos do AVA e gerados em arquivos auxiliares. A partir destes, usamos a análise de conteúdo para categorizar os dados textuais e agrupá-los em categorias conceituais. Segundo Julien (2008), esse método analítico é uma forma de reduzir dados e buscar seus significados por meio de uma leitura acurada do texto, que deve ser interpretado de acordo com seu contexto.

Os diálogos coletados incluíram diferentes disciplinas, de fases iniciais e finais do curso, de modo a abarcar alunos em diferentes etapas de sua formação e em disciplinas que envolvem conteúdos variados. A Tabela 1 apresenta uma visão geral dos dados coletados. 
Tabela 1 - Visão geral dos dados coletados no AVA

\begin{tabular}{l|c|c|c}
\hline Disciplina & $\begin{array}{c}\text { Fase do } \\
\text { curso }\end{array}$ & $\begin{array}{c}\text { Quantidade de comentários } \\
\text { enviados pelos alunos ao professor }\end{array}$ & $\begin{array}{c}\text { Quantidade de mensagens } \\
\text { enviadas pelos alunos ao colegas }\end{array}$ \\
\hline $\begin{array}{l}\text { Fundamentos para Sistemas } \\
\text { de Informação }\end{array}$ & 1 & 151 & 2 \\
\hline $\begin{array}{l}\text { Organização de } \\
\text { Computadores }\end{array}$ & 1 & 175 & 4 \\
\hline Prática Profissional em TI & 1 & 141 & 7 \\
\hline Estudo de Caso & 5 & 390 & 1 \\
\hline Gerência de Projetos & 5 & 149 & 1 \\
\hline Gestão Financeira I & 5 & 351 & 10 \\
\hline Total geral & & $\mathbf{1 . 3 5 7}$ & $\mathbf{2 5}$ \\
\hline
\end{tabular}

As categorias que agruparam as motivações e interesses dos alunos em suas comunicações são descritas e analisadas a seguir.

\section{Análise das interações no AVA}

A primeira e mais evidente constatação da observação da Tabela 1 é que as interações pelo AVA ocorrem muito mais entre alunos e professores do que dos alunos entre si. Isso pode ocorrer porque a metodologia de ensino da instituição privilegia trabalhos individuais, com raras atividades em grupo. Além disso, pode indicar que o AVA é um espaço que atende mais as necessidades formais, que envolvem as funções didáticas da interação aluno-professor. As interações entre alunos podem se dar por outros meios ou ambientes mais informais, conforme demonstrado mais adiante.

$\mathrm{Na}$ análise qualitativa das comunicações, deparamo-nos com alguns padrões que revelam as motivações e interesses dos alunos para interagir no ambiente virtual, agrupados em categorias assim formuladas: (a) dúvidas operacionais, de conteúdo e de avaliação, (b) iniciativas para a colaboração, (c) desejo de afiliação ao grupo, (d) manifestações de afetividade, (e) negociação e conflitos, e, por fim, (f) desejo de privacidade e não supervisão. A seguir, descrevemos e analisamos essas categorias, sintetizadas na Figura 1.

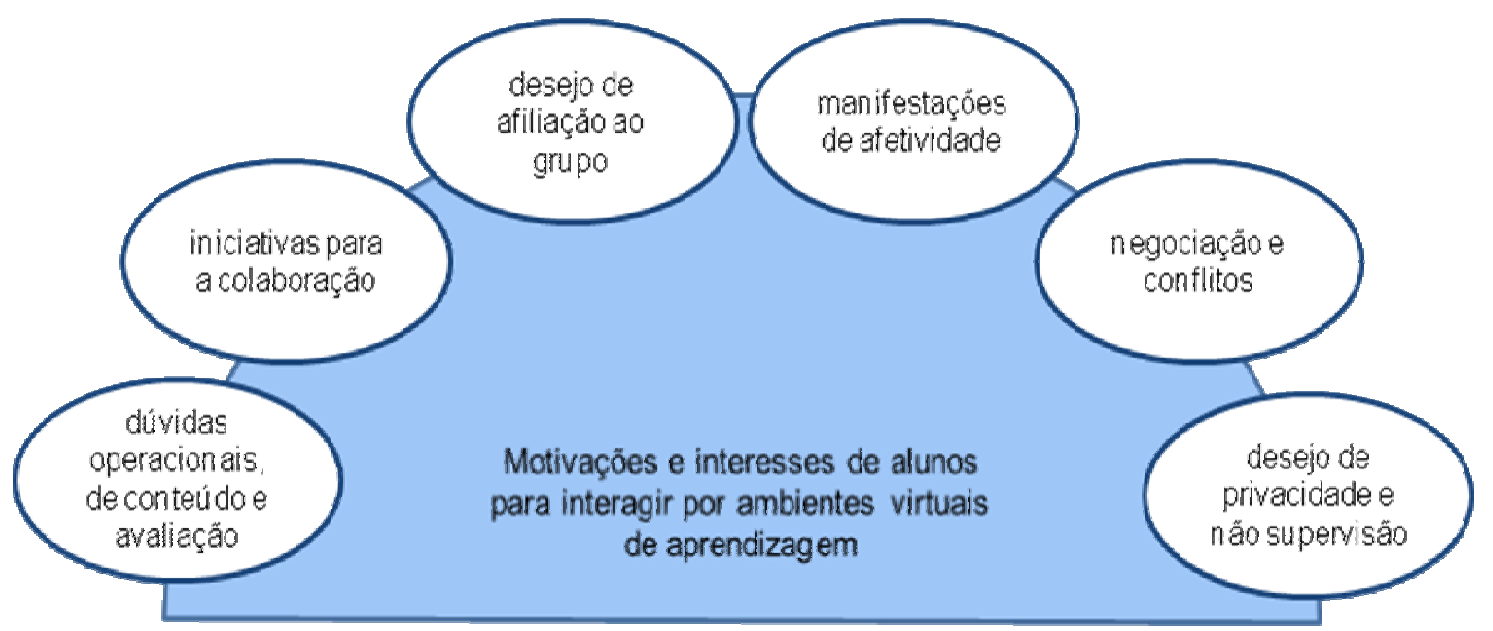

Figura 1 - Motivações e interesses dos alunos para interação em AVAs. 


\subsection{Dúvidas operacionais, de avaliação e de conteúdo}

Ao ingressar no curso, a maioria dos alunos desconhece o funcionamento da dinâmica dessa modalidade de ensino. Por isso, nas turmas de alunos calouros, aparecem com maior predominância as dúvidas quanto à operação das ferramentas do AVA e também sobre a metodologia de estudos, sobretudo, o que se refere à remessa de avaliações, aos compromissos e cronogramas, à entrega de materiais impressos e aos encontros presenciais. Esse tipo de interação evidencia-se na fala dos alunos ${ }^{1}$ :

Olá gostaria de uma informação referente ao material didático, se vai ser entregue na residência ou disponível no campus. E também referente ao local das provas presenciais.

Professor, não estou conseguindo enviar a AD1 [avaliação a distância 1] [...] como eu faço? poderia me ajudar?

Observamos que as dúvidas operacionais, apesar de relativamente simples, são motivo de ansiedade para o aluno ingressante. À medida que são esclarecidas, os alunos manifestam certa tranquilidade. Isso pode ser observado na fala do aluno:

Ok professor, fico muito agradecido e agora começo a entender melhor o funcionamento do curso. Vou colocar as minhas respostas no campo exposição, conforme sua orientação e ficarei aguardando seus comentários. Mais uma vez obrigado.

Este padrão de interação é explicado por Saraiva et al (2006), que afirmam que ao ingressar no estudo a distância o acolhimento, a sensação de fazer parte são elementos decisivos para superar a barreira tecnológica. Para superar os obstáculos, precisam ser feitos investimentos visando assessorar as dificuldades individual e coletiva

As dúvidas relacionadas ao conteúdo das disciplinas são mais fortemente exploradas pelos alunos mais avançados no curso, que tendem a explorar mais as ferramentas de interação para este propósito. Observamos, também, que enquanto os alunos inexperientes limitam-se a dizer que não compreenderam determinado conceito, os alunos mais avançados elaboram e detalham suas dúvidas de modo claro e objetivo.

Diferenças nos padrões de interação de alunos calouros e veteranos foram também observadas em estudo quantitativo realizado no mesmo contexto desta pesquisa. Nele, Mülbert e Schuhmacher (2009) apresentaram resultados que indicaram que os alunos, à medida que avançam seus estudos, amadurecem e transformam sua forma de interagir por meio do AVA. À medida que avança, o aluno altera a frequência e a forma de suas interações, que tendem a diminuir quando o aluno desenvolve confiança em sua própria capacidade de aprender com autonomia e aprende a utilizá-las com maior eficiência.

\subsection{Iniciativas para a colaboração}

Segundo Milne (2006), a interação social corresponde a uma parte cada vez mais significativa da aprendizagem, pois cada vez mais os estudantes se sentem motivados a aprender na interação com seus pares. Essa característica do estudante pede, então, por práticas pedagógicas baseadas na colaboração. A colaboração observada no ambiente 


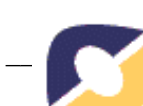

virtual manifesta-se como um fenômeno que ocorre tanto entre os alunos quanto entre aluno e professor. O desejo de colaborar, entre os alunos, evidencia-se muito claramente entre os iniciantes que, repetidas vezes, manifestam seu interesse em estabelecer trocas e parcerias com seus colegas. A fala do aluno, dirigindo-se por email aos seus colegas, representa esse interesse de troca de experiências na área de conhecimento do curso:

Pode contar comigo, aliás todos que nunca ouviram falar em MAINFRAME, COBOL, CLIPPER, QBASIC, tudo da minha época, estou aqui para somar e aprender.

A colaboração se estende além das atividades de construção de conhecimentos, como é o caso da aluna que avisa seus colegas sobre os prazos de cumprimento de uma atividade:

Olá colegas, amanhã é o último dia para o envio da AD [avaliação a distância]. Não vão se perder, eu estou apavorada pois é bem mais difícil quanto parece. Boa sorte a todos.

Moore (2007, p. 47) esclarece que a rede de colaboração estabelecida entre alunos afeta o processo de aprendizagem e influencia nos modos de interação. Os alunos entram em uma comunidade de ideias partilhadas na condição de principiantes e, apoiados por um professor (ou outra pessoa competente), assumem progressivamente a responsabilidade por seu próprio aprendizado. Quanto mais colaboram e interagem entre si, menos dependem da interação com o professor.

As iniciativas de interação para colaborar evidenciam-se como de interesse tanto daqueles que tem recursos a compartilhar como daqueles que usufruem das contribuições. Ao criar um clima colaborativo, relacionamentos são estabelecidos de modo que todos dele possam usufruir.

\subsection{Desejo de afiliação ao grupo}

Assim como as iniciativas de colaboração, nosso estudo identifica também um forte desejo por parte dos alunos de fazer parte de uma comunidade, de um grupo. Participar de um grupo é uma forma de estabelecer uma rede de colaborações, porém, os benefícios de fazer parte de um grupo podem ir além da colaboração nas tarefas. A participação em grupos pode, também, gerar sentimentos positivos de apoio, de coragem, de reforço para superação dos obstáculos e desafios. Isso se evidencia quando os alunos destacam o desafio que têm a alcançar juntos, como partícipes de um mesmo movimento e com uma necessidade de superação em comum pela frente. A fala das alunas a seguir representa esse fato:

Olá!!! Estou entrando em contato para desejar-lhe sucesso neste curso!!! Que possamos juntos alcançar os nossos objetivos através deste curso!

Olá turma, hoje posso dizer que estou mais tranquila, confesso que ontem quando entrei nas unidades das disciplinas fiquei preocupada, mas hoje estou mais tranquila e confiante. Espero que todos tenham um ótimo estudo e possamos nos ajudar uns aos outros 


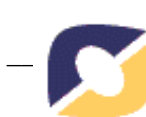

Segundo Mattar (2009, p. 116) a interação aluno/aluno gera motivação e atenção enquanto os alunos aguardam o feedback dos colegas e também diminui a sensação de isolamento do estudo a distância. Essa interação também desenvolve o senso crítico e a capacidade de trabalhar em equipe e, muitas vezes, cria a sensação de pertencer a uma comunidade. Nos diálogos observados, o desejo de estabelecer redes de colaboração ficou evidente, tanto para colaborar na realização de tarefas em comum quanto para criar laços solidários e de apoio mútuo.

\subsection{Manifestações de afetividade positiva}

Além do conteúdo explícito das interações, identificamos que as mensagens carregam em si conteúdos afetivos que podem também revelar os interesses e motivações do aluno para interagir ${ }^{2}$. Segundo Longhi et al (2009), cognição e afetividade constituem elementos indissociáveis. Crenças, desejos e intenções exercem influências sobre os processos cognitivos e estes, por sua vez, ativam as dimensões afetivas do sujeito (Longhi et al, 2009).

Em nosso estudo, observamos que os alunos buscam expressar-se de modo afetivo. Várias comunicações carregam em si uma linguagem afetuosa e cordial, como a que podemos observar no depoimento do aluno a seguir. Nele, o aluno revela seu misto de satisfação e ansiedade, assim como agradece de modo afetuoso a contribuição do professor:

Agradeço de coração a avaliação que me foi dada, é um incentivo a mais para não desistir, estou muito ansioso à chegada da AP [avaliação presencial]. Quero que saiba que em toda minha vida de estudo nunca escrevi tanto assim, só cartas de amor [...] estou muito feliz por ter este começo genial.

As manifestações de agradecimento também se manifestam quando o aluno percebe que o professor vai além das suas atividades formais e demonstra preocupação com o sucesso do aluno.

Escrevo por dois motivos: Primeiro agradecer pelas contribuições acessórias, além do conteúdo específico, os textos extras e sua preocupação com andamento dos estudos, [...] é primordial para nosso desenvolvimento. Segundo, ao enviar minha AD [avaliação a distância] tive um problema no ulpload e fiz novo envio, creio que na segunda tentativa tudo tenha corrido bem. Agradeço pela dedicação e atenção.

Segundo Saraiva et al (2006), numa relação virtual, certas características e dimensões implícitas apontam formas de ser e de configurar sentidos, condições essas de grande significado, tais como a necessidade de estabelecimento de contatos, de ampliação de laços de afetividade com ênfase na imagem e voz de professores e alunos - atores desse processo - e a importância do contato face a face, mesmo que distantes em tempo e espaço (Saraiva et al, 2006, p. 489).

\subsection{Negociação e conflitos}

Os espaços de interação em programas de educação a distância apresentam, também, tensões que afetam o desenvolvimento das atividades educacionais. Os 


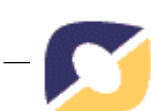

interagentes vivenciam incertezas e apreensões que permeiam as atividades educacionais desenvolvidas a distância (Saraiva et al, 2006). Então, assim como se apresentam desejos e necessidades de vivenciar o afeto, também surgem situações de conflito resultantes de divergências de interesses e/ou opinião. Isso foi observado pela emergência de situações de conflito, como a que expressa a aluna, em mensagem para seus colegas de turma, quando discorda do posicionamento do professor:

\begin{abstract}
Estou chocada com a correção da minha AP [avaliação presencial]. O professor não leva em consideração o raciocínio utilizado, só o resultado final. E tudo indica que a coordenação do curso vai deixar como está. Absurdo frente à mobilização de tantos alunos prejudicados.
\end{abstract}

Nesta situação, o conflito emerge, mas não é abordado diretamente com o agente que está do lado oposto do conflito, neste caso o professor. Em situações como essa, observamos que o aluno inicia diálogo com o professor buscando negociação. Isso pode envolver negociação de prazos, regras, critérios de avaliação, interpretação de questões de avaliação ou qualquer outra situação em que há interesses divergentes. Essa negociação se baseia, com frequência, em uma exposição de motivos que, pela ótica do aluno, justificam seus argumentos:

Professor,assim como o colega anterior, tive problemas que inviabilizaram a entrega da AD [avaliação a distância] no prazo. Eu e mais 7 colegas de trabalho tivemos uma infecção alimentar e fomos parar no hospital [...] Conto com sua compreensão.

Para Saraiva et al (2006), professor, tutor e monitor em EAD são agentes que assumem, no processo educacional, posições normalmente geradoras de tensão. Em consonância com nossas observações, em situações de conflito, verificamos que emergem as iniciativas de negociação. Uma forma frequentemente encontrada para lidar com os conflitos entre alunos e professor é a busca pela formação de alianças entre os alunos, que buscam agir de modo coordenado entre si para conseguir, em grupo, mais força em seus argumentos. Isso pode ser representado pela fala da aluna, que se comunica com seus colegas em busca de uma aliança e uma ação em conjunto:

Vamos exercer nosso direto de reclamar. Porque não é possivel a maioria da turma não entender a matéria.

Saraiva et al (2006) orientam que, mesmo sendo virtual, o cenário do processo educativo é vivo, móvel e vibrante. Está em permanente tensão e seus elementos desacomodam e afetam uns aos outros. As conexões que vão se estabelecendo originam-se de diferentes demandas, que não estavam previstas e necessitam criar saídas. Formam-se linhas de fuga e problematizações que se modificam em função de necessidades dos atores sociais. Neste sentido, nossas observações indicam que a negociação entre aluno e professor é uma das linhas de fuga encontradas para equacionar as situações inesperadas da vida acadêmica.

\title{
5.6 Desejo de privacidade
}

Observamos que, logo ao iniciar o curso, os alunos buscam formar redes de colaboração que se desenvolvem posteriormente fora do AVA. Isso nos leva a supor o 


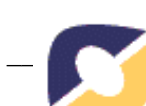

desejo dos alunos de interagir com seus pares fora dos espaços formais representados pelo ambiente virtual da instituição de ensino. Encontramos, nas comunicações entre alunos, diversos convites para interagir fora deste ambiente, em fóruns, chats ou redes sociais. Isto pode ser observado nas falas a seguir:

Fiz um chat no msn para que possamos interagir melhor, debatendo assuntos sobre as disciplinas e etc, o endereço do chat é [...]

Olá colegas. Quem tiver twitter e quiser podemos nos seguir

Esta saída para a interação em ambientes onde não há supervisão dos agentes do sistema formal de ensino revela o desejo que o grupo tem de privacidade $\mathrm{e}$ informalidade. Neste aspecto, o AVA serve apenas como o contato inicial, onde a rede inicialmente se forma, mas que, assim que possível, migra para espaços de maior liberdade. Essa necessidade de liberdade de interação é relatada como uma tendência por Downes (2010), que explica que a aprendizagem e a interação da "geração net" já se desenvolveu a partir do paradigma das redes digitais, onde a rede de relacionamentos informais é democrática, seus membros são autônomos, com liberdade para negociar e trocar informações. Assim sendo, a busca dos alunos por formar redes paralelas para interagir fora do ambiente virtual institucional favorece a criação de conexões mais livres e sem supervisão.

\section{Considerações finais}

A partir da análise do conteúdo das comunicações realizadas em um AVA, buscamos identificar as motivações e interesses do aluno para interagir por sua livre iniciativa. Essas motivações envolvem desde aspectos de integração social, quanto aqueles voltados para a melhoria do desempenho acadêmico e a solução dos problemas decorrentes do desafio de estudar a distância. Os interesses foram categorizados de modo a identificar em detalhes quais são os motivos para interagir. Todavia, é importante destacar que os interesses que categorizamos estão inter-relacionados. A interação que busca colaboração, por exemplo, parece estar também intimamente relacionada com o interesse de afiliação a grupos. Da mesma forma, a colaboração pode ser também um recurso importante para dar suporte aos alunos para vivenciar conflitos, e assim por diante. Destacamos, também, que o padrão de interatividade dos alunos altera-se à medida que os alunos avançam e aprimoram sua experiência no AVA.

Alunos iniciantes buscam mais pela afiliação e integração grupal, e quando esses objetivos já foram alcançados outras motivações podem emergir. Este é o caso das interações motivadas pelo conflito. Elas não ocorreram com os alunos que ainda estão consolidando seu padrão de interação e tendem a se manifestar em alunos que já tem mais experiências nas interações virtuais.

\section{Notas}

${ }^{1}$ Os comentários dos alunos foram registrados de modo idêntico ao encontrado no AVA. Correções de grafia ou pontuação não foram realizadas. Entre colchetes foram inseridos os significados de algumas siglas que fazem parte do jargão adotado pelos interagentes. 
2 Consideramos nesta categoria os contatos de afeto em sua forma positiva. Não consideramos como afeto as emoções ou estados de ânimo negativos ou conflitivos. $\mathrm{O}$ conflito é abordado em uma categoria em separado.

\section{Referências}

DOWNES, S. Learning Networks and Connective Knowledge. In: YANG, H.; YUEN, S. Collective Intelligence and E-Learning 2.0. New York: Information Science Reference, 2010.

JULIEN, H. Content analisys. In: GIVEN, L. M. (Ed.). The SAGE encyclopedia of qualitative research methods. Vols. 1 \& 2, Thousand Oaks, CA: Sage, 2008. p. 120-1.

LONGHI, M. T.; BEHAR, P. A.; BERCHT, M. A busca pela dimensão afetiva em ambientes virtuais de aprendizagem. In: BEHAR, P. A. (Org). Modelos pedagógicos em educação a distância. Porto Alegre: Artmed, 2009. p. 204-231.

MATTAR, J. Interatividade e aprendizagem. In: LITTO, F. M.; FORMIGA, M. (Org). Educação a distância: o estado da arte. São Paulo: Pearson, 2009. p. 112-120.

MOORE, Michael G.; KEARSLEY, Greg. Educação a distância. São Paulo: Thomson, 2007.

MÜLBERT, A. L.; SCHUHMACHER, V. R. Interaction Maturity of the Distance Learning Students. In: ICBL2009. Anais . v. 1. 2009, Florianópolis.

MILNE, A. J. Designing Blended Learning Space to the Student. In: OBLINGER, D. G (Ed). Learning spaces. EDUCAUSE. 2006. cap 12, p. 142-157.

OBLINGER, D. G. Space as a Change Agent. In: OBLINGER, D. G (Ed). Learning spaces. EDUCAUSE. 2006. cap. 1, p. 12-16.

SARAIVA , L. M.; PERNIGOTTI, J.; BARCIA, R. M.; LAPOLLI, E. M. Tensões que afetam os espaços de educação a distância. In: Revista Psicologia em Estudo, Maringá, v.11, n.3, p. 483-491, set/dez. 2006. http://www.scielo.br/pdf/pe/v11n3/v11n3a03.pdf.

SCHUTZ, William. Psicoterapia pelo encontro. Rio de Janeiro: Atlas, 1978.

TRIVIÑOS, Augusto Nibaldo Silva. Introdução à pesquisa em ciências sociais: a pesquisa qualitativa em educação. São Paulo: Atlas, 1992. 